19

\title{
Плазмон-стимулированное фотолегирование в тонкослойной структуре $\mathrm{As}_{2} \mathrm{~S}_{3}-\mathrm{Ag}$
}

\author{
() И.З. Индутный, В.И. Минько, Н.В. Сопинский ", П.М. Литвин \\ Институт фризики полупроводников им. В.Е. Лашкарёва НАН Украины, \\ 03028 Киев, Украина \\ ๑e-mail: sopinskyy@ua.fm, sopinsky@isp.kiev.ua \\ Поступила в редакцию 28.05.2019 г. \\ В окончательной редакции 05.07.2019 г. \\ Принята к публикации 18.07.2019 г.
}

\begin{abstract}
Впервые проведены исследования влияния возбуждения поверхностных плазмон-поляритонов на границе серебро-халькогенидное стекло на фотостимулированную диффузию серебра в халькогенид. Для возбуждения плазмонов использовалась высокочастотная алюминиевая дифракционная решетка с периодом $248.5 \mathrm{~nm}$, на которую наносилась двухслойная структура $\mathrm{Ag}-\mathrm{As}_{2} \mathrm{~S}_{3}$. Было установлено, что процесс фотостимулированной диффузии серебра в слой халькогенида ускоряется (т. е. фоточувствительность такой структуры возрастает), когда во время экспонирования на границе $\mathrm{Ag}-\mathrm{As}_{2} \mathrm{~S}_{3}$ возбуждается поверхностный плазмон-поляритон. Фиксация фотостимулированных изменений оптических характеристик структуры, в том числе и на начальной стадии процесса фотодиффузии, осуществлялась путем регистрации динамики изменений характеристик плазмонного возбуждения со временем экспонирования.
\end{abstract}

Ключевые слова: поверхностные плазмон-поляритоны, субволновые решетки, халькогенидное стекло, $\mathrm{Ag}$, $\mathrm{As}_{2} \mathrm{~S}_{3}$.

DOI: $10.21883 /$ OS.2019.11.48529.201-19

\section{Введение}

Открытый М.Т. Костышиным, Е.В. Михайловской и П.Ф. Романенко эффект фотографической чувствительности структур полупроводник-металл [1] послужил основой развития целой области исследований фотостимулированных процессов в поликристаллических и аморфных тонкослойных структурах [2], в частности фотостимулированного взаимодействия серебра с пленками халькогенидных стекол (ХC). На основе исследований механизма этого явления разработаны высокоразрешающие регистрирующие среды и технологии их практического использования в качестве неорганического резиста $[3,4]$, сред для голографии и интерференционной литографии $[5,6]$ записи информации [7], в оптотехнике $[8,9]$ и др.

Фотостимулированное взаимодействие в тонкопленочной структуре $\mathrm{XC}-\mathrm{Ag}$ является сложным явлением, включающим фотоэлектрические процессы, фотостимулированный массоперенос, химическое взаимодействие диффундирующих компонентов $[10,11]$. Эта сложность процесса обусловила и разную терминологию, которая применялась в литературе для данного явления, в частности, фотолегирование (photodoping) [10,12], фотодиффузия $[11,13]$, фоторастворение [14]. Каждый из этих терминов отражает определенные особенности процесса и все они могут использоваться как синонимы. Но первым и определяющим этапом этого явления является поглощение фотоактивного света в области границы $\mathrm{XC}-\mathrm{Ag}$, причем интенсивность процесса фотолегирова- ния серебром зависит от интенсивности света на этой границе.

Известно также, что на границе серебра с диэлектриком (которым по сути и является ХС) можно возбудить поверхностные плазмон-поляритоны (ППП), которые характеризуются локализацией электрического поля как раз у границы с диэлектриком $[15,16]$. Причем вблизи границы напряженность электромагнитного поля значительно выше, чем возбуждающего излучения, что может стимулировать фотолегирование и существенно повысить чувствительность структур $\mathrm{XC}-\mathrm{Ag}$. Такие исследования еще не проводились из-за трудностей возбуждения плазмонов на границе $\mathrm{Ag}$ с диэлектриком $\mathrm{c}$ высоким значением показателя преломления (около 3). Возбуждение ППП в таких условиях светом видимого диапазона спектра возможно посредством формирования на поверхности металла высокочастотной субволновой решетки с пространственной частотой около $4000 \mathrm{~mm}^{-1}$. Это и обусловило цель данной работы: установить корреляцию между возбуждением поверхностных плазмонполяритонов на границе халькогенидное стекло-серебро и фотолегированием металла в слой ХС. В качестве объекта исследований выбрана наиболее изученная структура $\mathrm{As}_{2} \mathrm{~S}_{3}-\mathrm{Ag}$, которая чаще всего используется в качестве модельной.

\section{Эксперимент}

Подложками для образцов служили алюминиевые решетки на полированных стеклянных пластинах, изго- 
товленные с помощью интерференционной литографии на основе вакуумных халькогенидных фоторезистов. Методика изготовления таких решеток подробно описана в наших предыдущих работах $[17,18]$. Дифракционные решетки, сформированные на термически осажденной в вакууме Al-пленке, покрывались диэлектрическим слоем $\mathrm{MgF}_{2}$ толщиной $40 \mathrm{~nm}$, на который осаждался непрозрачный слой серебра толщиной $80 \mathrm{~nm}$ (оба указанных слоя тоже наносились методом термического напыления в вакууме). Затем на серебро термически осаждался в вакууме слой халькогенида $\mathrm{As}_{2} \mathrm{~S}_{3}$ толщиной $70 \mathrm{~nm}$. Толщина слоев контролировалась в процессе осаждения с помощью градуированного кварцевого измерителя толщины КИТ-1 и измерялась после осаждения с помощью микроинтерферометра МИИ-4. Для определения формы профиля штрихов и глубины рельефа решетки использовался микроскоп атомных сил Dimension 3000 Scanning Probe Microscope (Digital Instruments Inc., Tonawanda, NY, USA).

Экспонирование структуры $\mathrm{As}_{2} \mathrm{~S}_{3}-\mathrm{Ag}$ осуществлялось со стороны халькогенида $p$-поляризованным излучением $\mathrm{He}-\mathrm{Ne}$-лазера $(\lambda=632.8 \mathrm{~nm})$. Как известно $[2,10,11]$, область светочувствительности структур $\mathrm{XC}-\mathrm{Ag}$ в основном корелирует со спектром поглощения соответствующего халькогенида. Поэтому структура $\mathrm{As}_{2} \mathrm{~S}_{3}-\mathrm{Ag}$ малочувствительна к излучению этой длины волны, поскольку пленки $\mathrm{As}_{2} \mathrm{~S}_{3}$ являются слабо поглощающими в этой области спектра. Это дает возможность достаточно подробно исследовать именно начальный этап фотолегирования в данной структуре.

Регистрация возбуждения ППП в структурах $\mathrm{As}_{2} \mathrm{~S}_{3}-$ $\mathrm{Ag}$ проводилась путем измерения зависимостей зеркального отражения $p$-поляризованого излучения того же лазера $R_{p}$ от угла падения $\theta$. Как экспонирование, так и регистрация возбуждения ППП в структурах $\mathrm{As}_{2} \mathrm{~S}_{3}-\mathrm{Ag}$ проводилась на стенде, смонтированном на основе гониометра Г5М и столика Федорова ФС-5, что позволяло менять угол падения $\theta$ в пределах $0-90^{\circ}$ с точностью $0.01^{\circ}$. Образец ориентировался таким образом, чтобы штрихи решетки были перпендикулярны плоскости падения света (азимутальный угол $\varphi=0^{\circ}$, точность установки $0.1^{\circ}$ ). Плотность мощности падающего на образец света составляла $I_{p}^{0} \cos \theta$, при экспонировании величина $I_{p}^{0}$ равнялась $32 \mathrm{~mW} / \mathrm{cm}^{2}$, а при регистрации возбуждения ППП для уменьшения влияния зондирующего света на исследуемую светочувствительную структуру она уменьшалась на два порядка и составляла $0.3 \mathrm{~mW} / \mathrm{cm}^{2}$.

\section{Полученные результаты и их обсуждение}

Для того чтобы возбудить ППП на поверхности серебряной решетки (на границе $\mathrm{As}_{2} \mathrm{~S}_{3}-\mathrm{Ag}$ ), нужно удовлетворить условие сохранения квазиимпульса с учетом компонент волновых векторов падающего излучения и плазмон-поляритонов, параллельных поверхности решетки, а также обратного вектора решетки. Поскольку в нашем случае обратный вектор решетки $G=2 \pi / d(d-$ период решетки) лежит в плоскости падения падающего излучения, это условие можно записать в скалярном виде [19]

$$
\operatorname{Re}\left(k_{\mathrm{SPP}}\right)=n k_{0} \sin \theta \pm m G,
$$

где $\operatorname{Re}\left(k_{\mathrm{SPP}}\right)$ - действительная часть комплексного волнового вектора ППП, $k_{0}=2 \pi / \lambda-$ волновой вектор падающего излучения с длиной волны $\lambda ; m$ - дифракционный порядок, целое число $m \neq 0$; мы будем ограничиваться только первым дифракционным порядком, $m=1) ; n=\sqrt{\varepsilon}-$ показатель преломления окружающей среды с диэлектрической проницаемостью $\varepsilon$. В нашем случае диэлектрической средой, которая граничит с поверхностью $\mathrm{Ag}$, является $\mathrm{As}_{2} \mathrm{~S}_{3}$. В этой работе мы будем использовать решетки с небольшой глубиной модуляции (до 25\%), поэтому для приблизительной оценки величины волнового вектора ППП можно применить выражение, полученное для случая плоской границы раздела полубесконечных сред [16]. Кроме того, его можно упростить, учитывая, что для Ag в этой области спектра абсолютная величина действительной части диэлектрической проницаемости (которая является отрицательной) значительно больше мнимой части: $\left|\varepsilon_{1}\right| \gg\left|\varepsilon_{2}\right|$. В этом приближении

$$
\operatorname{Re}\left(k_{\mathrm{SPP}}\right)=n k_{0} \sqrt{\frac{\varepsilon_{1}}{\left(\varepsilon_{1}+\varepsilon\right)}} .
$$

Решив уравнение (1) с учетом (2) относительно $\sin \theta$, можно определить резонансный угол падения $\theta_{r}$, при котором можно возбудить ППП для данной решетки, выбранной длины волны и данной диэлектрической среды. И наоборот, исходя из требуемого значения резонансного угла падения можно определить необходимый для этого период решетки. При проведении этих расчетов значение $\varepsilon_{1}$ для $\mathrm{Ag}$ было взято из работы [20] $\left(\varepsilon_{1}=-18.28\right)$, а показатель преломления $n$ для $\mathrm{As}_{2} \mathrm{~S}_{3}$ из [2] $(n=2.40)$. Следует отметить, что $\theta_{r}$ является углом падения луча в слое ХС на поверхность серебра. Угол падения луча в воздухе на слой ХC $\left(\theta_{a}\right)$ можно определить с помощью закона Снеллиуса. Для удобства измерений необходимо было ограничиться небольшими значениями $\theta_{a}\left(\right.$ менее $\left.30^{\circ}\right)$. Установлено, что в нашем случае для этого необходимы решетки с периодом меньшим $250 \mathrm{~nm}$.

Учитывая результаты этого анализа, мы изготовили образцы, в которых период решетки составил $248.5 \mathrm{~nm}$. На рис. 1 приведены АСМ изображения и поперечное сечение такого образца с глубиной модуляции около $25 \%$.

В среде воздуха $(n=1)$ для таких высокочастотных решеток выполняется условие $\lambda / d>$ $>n\left[\varepsilon_{1} /\left(\varepsilon_{1}+1\right)\right]^{1 / 2}+1 \quad$ и возбуждений ППП на границе $\mathrm{Ag}$-воздух не существует во всем возможном интервале углов падения [21]. На рис. 2 (кривая 1) показана угловая зависимость зеркального отражения 

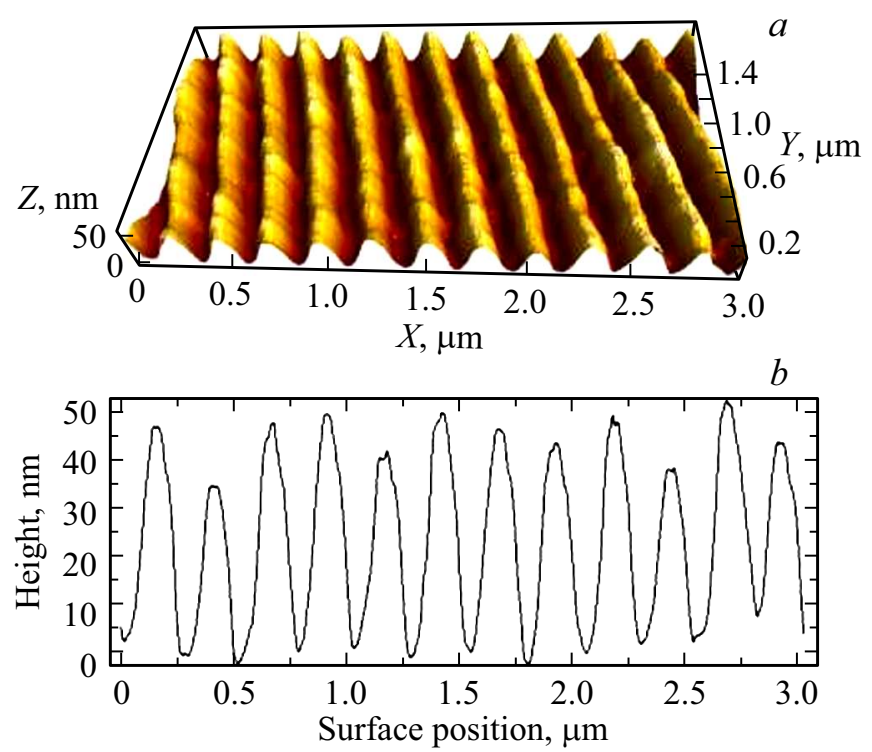

Рис. 1. АСM изображение $(a)$ и поперечное сечение $(b)$ решетки с периодом $248.5 \mathrm{~nm}$.

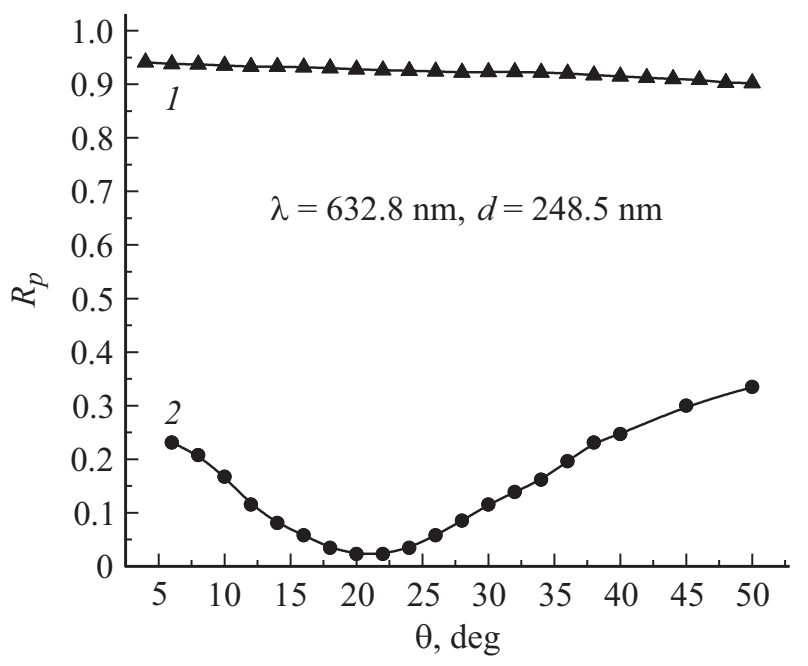

Рис. 2. Зависимость $R_{p}$ от угла падения для серебряной решетки с периодом $248.5 \mathrm{~nm}$ (кривая 1) и для той же решетки, покрытой слоем $\mathrm{As}_{2} \mathrm{~S}_{3}$ толщиной $70 \mathrm{~nm}$ (кривая 2).

$p$-поляризованного света от такой решетки, покрытой серебром. Наблюдается плавная угловая зависимость $R_{p}$, характерная для плоского образца. Однако для образцов, где серебро покрыто слоем $\mathrm{As}_{2} \mathrm{~S}_{3}$ достаточной толщины, на границе $\mathrm{Ag}-\mathrm{As}_{2} \mathrm{~S}_{3}$ выполняется условие $n\left[\varepsilon_{1} /\left(\varepsilon_{1}+n^{2}\right)\right]^{1 / 2}+1 \geq \lambda / d \geq n\left[\varepsilon_{1} /\left(\varepsilon_{1}+n^{2}\right)\right]^{1 / 2} \quad$ и возможно возбуждение ППП [21]. В нашем случае толщина слоя $\mathrm{As}_{2} \mathrm{~S}_{3}$ составляет $h=70 \mathrm{~nm}$, соответственно оптическая толщина $n h=168 \mathrm{~nm}$ и почти все электрическое поле плазмонного возбуждения сконцентрировано в слое ХC. Поэтому для определения резонансного угла падения на границе $\mathrm{Ag}-\mathrm{As}_{2} \mathrm{~S}_{3}$ можно использовать с достаточной точностью приведенные выше выражения для полубесконечной диэлектрической среды. Рассчитанное с учетом закона Снеллиуса значение резонансного угла падения луча в воздухе на слой ХС данного образца для указанных выше значений $\varepsilon_{1}$ и $n$ равняется $\theta_{a}=20.7^{\circ}$.

На рис. 2 кривая 2 соответствует угловой зависимости $R_{p}$ для структуры высокочастотная $\mathrm{Ag}$ решетка-слой $\mathrm{As}_{2} \mathrm{~S}_{3}$. Наблюдается глубокий минимум отражения при значении угла падения около $21^{\circ}$, что почти совпадает с рассчитанным положением $\theta_{a}$. Это свидетельствует о том, что использованные приближения в данном случае достаточно корректны. Для того чтобы исследовать взаимосвязь между фотолегированием и возбуждением ППП на границе $\mathrm{Ag}-\mathrm{As}_{2} \mathrm{~S}_{3}$, тождественные образцы экспонировались неослабленным лучом лазера с плотностью мощности $I_{p}^{0} \cos \theta\left(I_{p}^{0}=32 \mathrm{~mW} / \mathrm{cm}^{2}\right)$ в течение различных промежутков времени, после каждого экспонирования сканировалась угловая зависимость $R_{p}$, при этом величина $I_{p}^{0}$ составляла $0.3 \mathrm{~mW} / \mathrm{cm}^{2}$.

На рис. 3 кривые 1-5 отражают динамику изменения характеристик плазмонного возбуждения от начального, неэкспонированного, образца (кривая 1) до экспонированного в течение $50 \mathrm{~s}$. Видно, что с ростом экспозиции минимум отражения сдвигается в сторону больших значений угла падения, при этом его глубина уменьшается, полуширина растет, растет также величина отражения во всем исследуемом диапазоне углов падения. Экспонирование образцов в этом случае осуществлялось излучением, падающим перпендикулярно поверхности образца $\left(\theta_{\exp }=0^{\circ}\right)$, т. е. во время экспонирования ППП не возбуждался.

На рис. 4 представлены аналогичные результаты для тождественных образцов, которые экспонировались тем же излучением, но под углом $\theta_{\exp }=21^{\circ}$, что соответствует резонансному углу возбуждения ППП. При этом поверхностная плотность интенсивности падающего све-

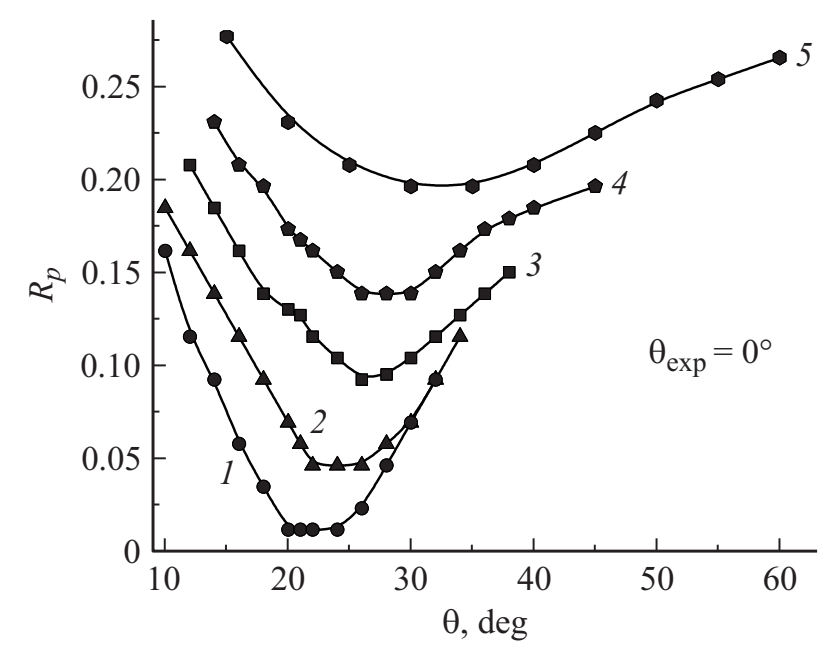

Рис. 3. Зависимость $R_{p}$ от угла падения для структуры серебряная решетка $-70 \mathrm{~nm} \mathrm{As} \mathrm{S}_{3}$ : неэкспонированной (кривая 1) и экспонированной в течение 10 (2), 20 (3), 30 (4) и $50 \mathrm{~s}$ (5). Экспонирующий луч перпендикулярен к поверхности образца $\left(\theta_{\exp }=0^{\circ}\right)$. 


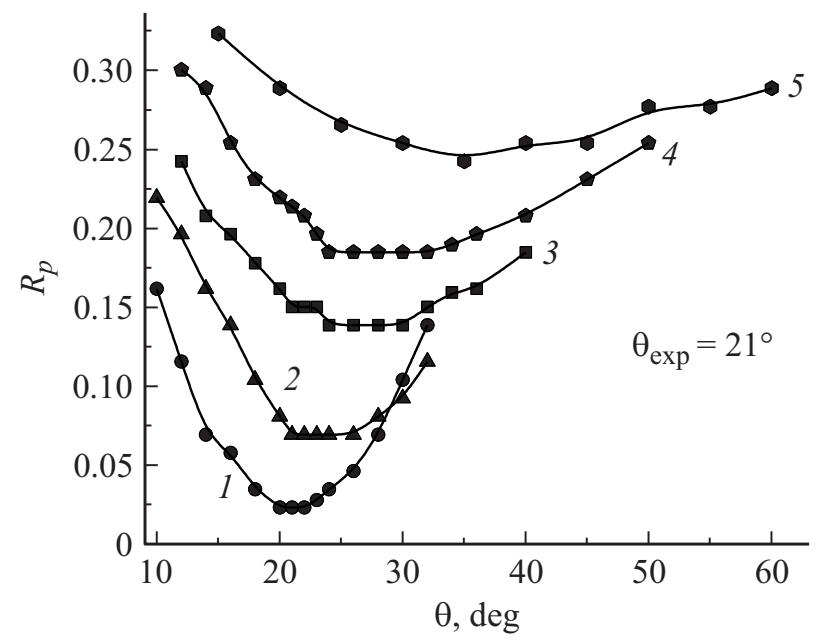

Рис. 4. Результаты, аналогичные рис. 3 , но для экспонирования под углом $21^{\circ}$ : неэкспонированная структура (кривая 1), экспонированная в течение 10 (2), 20 (3), 30 (4) и $50 \mathrm{~s}(5)$.

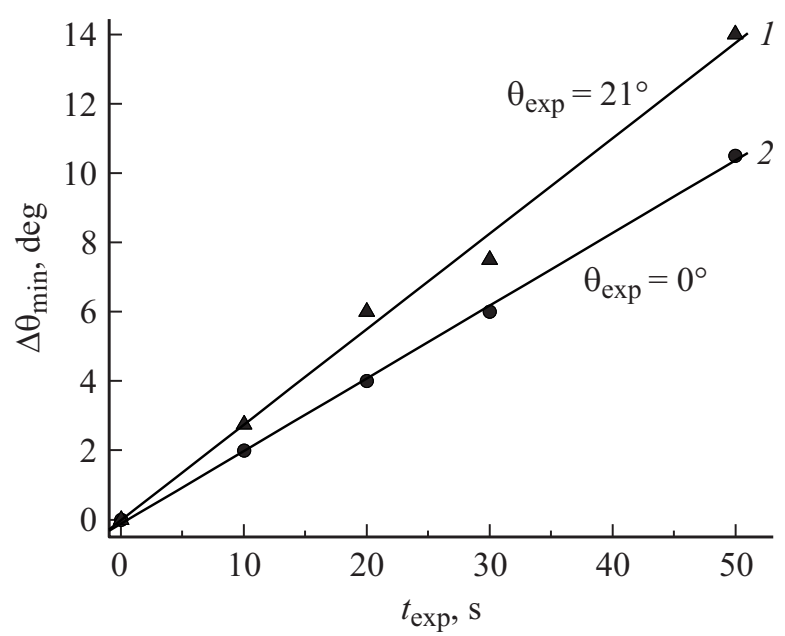

Рис. 5. Зависимость углового смещения $\left(\Delta \theta_{\min }\right)$ минимума $R_{p}$ от времени экспонирования образцов под углом $21^{\circ}(1)$ и по нормали к его поверхности (2).

та уменьшалась на 7\% по сравнению с нормальным падением, но интенсивность электромагнитного поля у границы $\mathrm{Ag}-\mathrm{As}_{2} \mathrm{~S}_{3}$ росла благодаря возбуждению ППП. Из рисунка видно, что в данном случае деградация минимума отражения, связанного с возбуждением ППП, происходит эффективнее с увеличением времени экспонирования, несмотря на несколько меньшую поверхностную плотность интенсивности падающего света: смещение минимума ППП, уменьшение его глубины, рост полуширины и величины отражения во всем исследуемом диапазоне углов падения происходит быстрее по сравнению с экспонированием при $\theta_{\exp }=0^{\circ}$. На рис. 5 показаны зависимости сдвига минимума $\left(\Delta \theta_{\min }\right)$ от времени экспонирования образцов под углом $21^{\circ}(1)$ и нормально к его поверхности (2). Наблюдается $33 \%$ рост $\Delta \theta_{\min }$ в результате экспонирования под углом, соответствующим возбуждению ППП, по сравнению с экспонированием нормально к поверхности образца. При временах экспонирования $\geq 30-50$ s в области освещения появляется видимое глазом пятно, соответствующее изменению оптических характеристик структуры вследствие фотолегирования серебра в $\mathrm{As}_{2} \mathrm{~S}_{3}$. Это видимое изменение появляется при меньших временах экспонирования и более выражено для образца, экспонированного под углом $21^{\circ}$.

Как показано в предыдущих работах $[11,22]$, в результате фотостимулированной диффузии $\mathrm{Ag}$ в $\mathrm{As}_{2} \mathrm{~S}_{3}$ происходят существенные изменения оптических констант легированного слоя ХС, в частности растет величина коэффициента поглощения в области края межзонных переходов и увеличивается показатель преломления. Рост показателя преломления среды, граничащей с металлом, должен сопровождаться увеличением резонансного угла $\theta_{a}$, соответствующего возбуждению ППП в такой структуре. Такое смещение резонанса со временем экспонирования и наблюдается в эксперименте (рис. 3-5). Если допустить, что серебро равномерно распределяется по толщине в слое $\mathrm{As}_{2} \mathrm{~S}_{3}$, соответственно равномерно изменяя показатель преломления, то, используя формулы (1) и (2), можно оценить, насколько изменится $n$ легированного слоя $\mathrm{As}_{2} \mathrm{~S}_{3}$. Получим, что за $50 \mathrm{~s}$ экспонирования $n$ изменится от 2.40 до 2.49 для образца, экспонированного нормально к его поверхности и до 2.52 для экспонированного под углом $21^{\circ}$.

Если предположить, что показатель преломления изменяется пропорционально концентрации серебра (по крайней мере на начальном этапе при малых концентрациях) и использовать экспериментальные значения $n$ для нелегированных и фотолегированных слоев $\mathrm{As}_{2} \mathrm{~S}_{3}$ с известной концентрацией серебра [11], то можно оценить, какая эффективная толщина серебра фоторастворилась в слое $\mathrm{As}_{2} \mathrm{~S}_{3}$ толщиной $70 \mathrm{~nm}$, нанесенном на серебряную решетку за $50 \mathrm{~s}$ экспонирования. Получим значение $3.2 \mathrm{~nm}$ при экспонировании нормально к поверхности образца и $4.2 \mathrm{~nm}$ при освещении под углом $21^{\circ}$, т.е. увеличение на треть вследствие возбуждения ППП.

Однако такие оценки расходования серебра являются лишь приблизительными, поскольку распределение концентрации фотодиффундирующего серебра на начальном этапе не является равномерным по толщине слоя $\mathrm{As}_{2} \mathrm{~S}_{3}$ [11]. В течение этого начального этапа (так называемый индукционный период) поток серебра мало интенсивный и происходит формирование промежуточного легированного слоя оптимальной концентрации, что соответствует атомному содержанию серебра в $32 \%$. Индукционный период переходит в основной этап фотолегирования с интенсивной фотодиффузией серебра, когда оптимально легированный слой достигает толщины $18 \mathrm{~nm}$, при этом растворяется $6 \mathrm{~nm}$ серебра [23]. При дальнейшем экспонировании этот концентрационный профиль с крутым передним фронтом распространяется в пленке $\mathrm{As}_{2} \mathrm{~S}_{3}$, пока не достигнет внешней границы пленки или не иссякнет слой Ag. При этом кинетика 
процесса выходит на насыщение. Таким образом, в нашем случае мы исследовали фактически начальный этап фотолегирования, который в предыдущих работах почти не исследовался.

Еще одним результатом фотостимулированной диффузии $\mathrm{Ag} \mathrm{в} \mathrm{As}_{2} \mathrm{~S}_{3}$ в течение начального этапа является увеличение полуширины резонансной кривой ППП и уменьшение глубины минимума отражения. Этот эффект может быть связан с неоднородностью фронта диффузии - диффузия серебра начинается в наиболее дефектных точках границы $\mathrm{Ag}-\mathrm{As}_{2} \mathrm{~S}_{3}$ [24,25]. В результате поверхность металлической решетки становится шероховатой, причем со временем экспонирования шероховатость растет, что препятствует эффективному возбуждению ППП.

\section{Заключение}

В работе впервые экспериментально показано, что возбуждение ППП на границе $\mathrm{Ag}-\mathrm{As}_{2} \mathrm{~S}_{3}$ ускоряет процесс фотостимулированной диффузии серебра в слой халькогенида, то есть способствует повышению фоточувствительности такой структуры. Причем с помощью возбуждения ППП можно не только стимулировать фотолегирование, но и регистрировать изменения оптических характеристик структуры вследствие фотодиффузии, в том числе и на начальной стадии процесса, когда видимые изменения еще отсутствуют.

\section{Конфликт интересов}

Авторы заявляют, что у них нет конфликта интересов.

\section{Список литературы}

[1] Костышин М.Т., Михайловская Е.В., Романенко П.Ф. // ФTT. 1966. T. 8. № 2. C. 571; Kostyshin M.T., Mikhailovskaya E.V., Romanenko P.F. // Sov. Phys. Solid State. 1966. V. 8. N 2. P. 451.

[2] Индутный И.З., Костышин М.Т., Касярум О.П., Минько В.И., Михайловская Е.В., Романенко П.Ф. Фотостимулированные взаимодействия в структурах металл-полупроводник. Киев: Наукова думка, 1992. 240 с.

[3] Yoshikawa A., Ochi O., Nagai H., Mizushima Y. // Appl. Phys. Lett. 1976. V. 29. N 10. P. 677. doi 10.1063/1.88899

[4] Tai K.L., Vadimsky R.G., Kemmerer C.T., Wagner J.S., Lamberti V.E., Timko A.G. // J. Vac. Sci. Technol. 1980. V. 17. N 5. P. 1169 . doi $10.1116 / 1.570634$

[5] Indutnyi I.Z., Stronski A.V., Kostioukevich S.A., Romanenko P.F., Shepeljavi P.E., Robur I.I. // Opt. Eng. 1995. V. 34. N 4. P. 1030. doi 10.1117/12.197144

[6] Mitkova M., Kozicki M.N. // J. Non-Cryst. Solids 2002. V. 299-302. Pt. 2. P. 1023. doi 10.1016/S0022-3093(01)01068-7

[7] Yamamoto Y., Itoh T., Hirose Y., Hirose H. // J. Appl. Phys. 1976. V. 47. N 8. P. 3603. doi 10.1063/1.323165

[8] Костышин М.Т., Кулиш Н.Р., Лисица М.П., Романенко П.Ф. // УФЖ. 1988. Т. 33. № 5. С. 704.
[9] Hajto J., Ewen P.J.S., Belford R.E., Owen A.E. // Thin Solid Films. 1991. V. 200. N 2. P. 229. doi 10.1016/00406090(91)90195-4

[10] Kolobov A.V., Elliott S.R. // Adv. Phys. 1991. V. 40. N 5. P. 625. doi 10.1080/00018739100101532.

[11] Индутный И.3. // ЖНиПФиК. 1994. Т. 39. № 6. С. 65.

[12] Murakami Y., Wakaki M. // Thin Solid Films 2013. V. 542. P. 246. doi 10.1016/j.tsf.2013.06.013

[13] Sakaguchi Y., Asaoka H., Mitkova M. // J. Appl. Phys. 2017. V. 122. N 23. P. 235105-1-12. doi 10.1063/1.5000858

[14] Khan P., Xu Y., Leon W., Adarsh K.V., Vezenov D., Biaggio I., Jain H. // J. Non-Cryst. Solids. 2018. V. 500. P. 468. doi 10.1016/j.jnoncrysol.2018.09.001

[15] Поверхностные поляритоны: Электромагнитные волны на поверхностях и границах раздела сред / Под ред. Аграновича В.М., Миллса Д.Л. М.: Наука, 1985. 525 с.

[16] Дмитрук Н.Л., Литовченко В.Г., Стрижевский В.Л. Поверхностные поляритоны в полупроводниках и диэлектриках. Киев: Наукова думка, 1989. 376 с.

[17] Данько В.А., Индутный И.З., Минько В.И., Шепелявый П.Е. // Автометрия 2010. Т. 46. № 5. С. 103; Dan'ko V.A, Indutnyi I.Z., Min'ko V.I., Shepelyavyi P.E. // Optoelectron. Instrument. Proc. 2010. V. 46. N 5. P. 483. doi 10.3103/S8756699011050116

[18] Dan'ko V., Dmitruk M., Indutnyi I., Mamykin S., Myn'ko V., Lukaniuk M., Shepeliavyi P., Lytvyn P. // Nanoscale Res. Lett. 2015. V. 10. Pap. 497. doi 10.1186/s11671-015-1203-x

[19] Hibbins A.P., Sambles J.R., Lawrence C.R. // J. Mod. Opt. 1998. V. 45. N 5. P. 1019. doi 10.1080/09500349808230894

[20] Johnson P.B., Christy R.W. // Phys. Rev. B. 1972. V. 6. N 12. P. 4370. doi 10.1103/PhysRevB.6.4370

[21] Gazzola E., Brigo L., Zacco G., Zilio P., Ruffato G., Brusatin G., Romanato F. // Plasmonics 2014. V. 9. N 4. P. 867. doi 10.1007/s11468-013-9624-9

[22] Индутный И.З., Стеиун А.И. // Опт. и спектр. 1991. Т. 71. № 1. C. 83.

[23] Костышин М.Т., Касярум О.П., Кудрявцев А.А. // УФЖ. 1983. T. 28. № 5. C. 710.

[24] Murakami Y., Wakaki M., Kawabata S. // Phys. Stat. Sol. (c) 2008. V. 5. N 5. P. 1283. doi 10.1002/pssc.200777797

[25] Sava F., Popescu M., Lórinczi A., Velea A. // Phys. Stat. Sol. (b) 2013. V. 250. N 5. P. 999. doi 10.1002/pssb.201248517 